\title{
ELOGIO DEL MAESTRO
}

Maestros y discípulos. Anatomía de una influencia. Por Fernando Bárcena. Madrid. Ápeiron Ediciones, 2020.

P de Profesor. Por Jorge Larrosa. Buenos Aires, Noveduc Libros, 2018.

Esperando no se sabe qué. Sobre el oficio de profesor. Por Jorge Larrosa. Barcelona, Candaya Abierta, 2019.

El profesor artesano. Materiales para conversar sobre el oficio. Por Jorge LARRosa. Barcelona, Laertes, 2020.

Estos libros, publicados en los tres últimos años, provienen de un gremio con el que cohabitamos a diario en las universidades pero que tal vez no llegan con facilidad a los historiadores de la educación, dada la fragmentación de gremios académicos en que se ha disuelto la vieja armonía de los saberes pedagógicos. Sin embargo, sus planteamientos y sus contenidos no solo están plagados de referencias historiográficas, sino que se construyen ellos mismos desde supuestos asociados a las condiciones de la historicidad de los temas que abordan, en los discursos en que se originan y sustentan y en los materiales de que se sirven para argumentar e implementar los narratorios. Es por todo ello por lo que interesan a los historiadores de la educación y por lo que tiene sentido que se recensionen aquí, en la revista Historia y Memoria de la Educación.

Recientemente, sus dos autores han puesto en escena una sesión online, en la que se presentaba la obra de Fernando Bárcena y en la que ejercía de moderador principal Jorge Larrosa, colegas ambos, el uno de la Universidad Complutense de Madrid y el otro de la Universidad de Barcelona, que se pueden adscribir a un mismo «colegio invisible», para decirlo en la terminología de Solla Price, que no sabría yo nominar aunque haya compartido con ellos, de manera intermitente pero desde hace ya cierto tiempo, algunas sesiones de análisis y debate sobre estas y otras cuestiones conexas en el marco de la Red Internacional de Hermenéutica Educativa (RIHE), constituida en el CEINCE en el año 2008, de la que 
forman parte historiadores y filósofos de España, Italia y México, con participación en ocasiones de profesores de Portugal. Una red que ha celebrado reuniones académicas sobre diversos temas en los tres países que la fundaron y que ha producido ya varias publicaciones colectivas de interés para nuestra disciplina.

El libro de Fernando Bárcena adopta el estilo de ensayo y fue finalista del conocido Premio Diderot de Ensayo 2020. Escrito en registros que combinan en buena armonía la filosofía con la literatura, se nuclea en torno al análisis de las relaciones maestro-discípulo y trata de plantear esta cuestión, a la altura de nuestro tiempo, desde la lógica de la legitimación que planteara en el siglo pasado, a comienzos de la década de los sesenta, la conocida obra de George Gusdorf ¿Para qué los profesores?, con la que el autor entabla dialogo en varios pasajes del texto. El libro de Gusdorf se publicó cuando la revolución tecnológica audiovisual parecía amenazar o trastocar el rol tradicional de los enseñantes. ${ }^{1}$ La obra que aquí comentamos entra en escena cuando la revolución de lo digital pretende servir de panacea que podría instrumentar un gran dispositivo tecnológico que cubriría las expectativas globales del sistema de enseñanza/aprendizaje, incluso en las crisis que desafíen a los modelos modernos pero aún clásicos, como parece incoarse en las respuestas dadas recientemente por muchas organizaciones a las necesidades derivadas del impacto de la pandemia en las esferas que afectan a de la gobernanza de la escuela y a la gestión de los programas de educación no formal. El autor ha escrito este libro antes de presentarse la pandemia, aunque preguntarse de nuevo acerca del para qué de los profesores vuelve a tener sentido, si bien no sea este el leitmotiv que motiva y articula el discurso de la obra del profesor Fernando Bárcena, ni tampoco el trasunto de la trilogía de su interlocutor Jorge Larrosa, quien también ha escrito sus textos con anterioridad a la reciente e inesperada situación.

Hace ahora diez años que Antonio Nóvoa, en la conferencia de clausura del XI Coloquio Nacional de Historia de la Educación, celebrado en El Burgo de Osma/Soria, en 2011, evento que versó precisamente sobre el

\footnotetext{
${ }^{1}$ George Gusdorf, ¿Para qué los profesores? (Madrid: Cuadernos para el Diálogo, 1975).
} 
tema Arte y Oficio de Enseñar, ${ }^{2}$ habló de una nueva "vuelta de los profesores». Los profesores siempre vuelven. Según él, tras el relativo fracaso de las reformas tecnológicas, curriculares y burocráticas emprendidas por diversos gobiernos durante las últimas décadas, los reformadores actuales de la educación escolar giraban su mirada otra vez hacia los docentes. A la pregunta que le formulamos en la publicación Papeles del CEINCE 09 acerca de la cuestión, el conocido historiador y comparatista respondía como sigue.

En 1986 defendí en la Universidad de Ginebra mi tesis doctoral que luego se publicó con el título Le Temps des Professeurs. Argumenté entonces que los años veinte del siglo último, los del desarrollo de la llamada Educación Nueva, constituyeron también los de afirmación y consolidación de la profesión docente.

Hoy, después de un siglo, los docentes adquieren una nueva centralidad. Ello coincide con la renovación de las ideas y propuestas que reformulan los principios de la modernidad pedagógica. Asistimos pues a un nuevo tiempo de los profesores, un tiempo en el que después de ciertas desilusiones con respecto a la ciencia de la educación, a las reformas del currículum, a las nuevas tecnologías y a la renovada gestión de la escuela, miramos una vez más hacia los profesores. ¿Cómo podemos pensar este tiempo nuevo? ¿Qué consecuencias tendrá para la identidad de la profesión docente? ${ }^{3}$

Tornar en el tiempo no es siempre un rictus arcaizante, como pudiera pensarse al retomar la tradición de un oficio milenario como tema de reflexión. En la presentación online del libro del profesor Bárcena, al igual que en el texto, se recurre reiteradas veces a los clásicos del magisterio como Confucio, Sócrates, Montaigne... Por su parte, los «elogios del profesor» que publicitan las obras de Jorge Larrosa tienen también sólidos anclajes en la larga duración del tiempo histórico que sirve de marco para sedimentar, desde la remota genealogía de la profesión, los códigos del viejo y siempre nuevo oficio de maestro. Algo se está moviendo pues

\footnotetext{
2 Pablo Celada Perandones (ed.), Arte y oficio de enseñar (Berlanga de Duero-El Burgo de Osma: CEINCE-SEDHE, 2011), 2 vols.

3 Antonio Novoa, «La vuelta de los profesores», Papeles del Ceince 9 (2011): 4.
} 
en este giro hermenéutico que regresa, como los ríos lo hacen a veces a sus fuentes de origen, a repensar el poder de influencia intelectual y moral que los maestros ejercieron y ejercen sobre sus discípulos, el impacto de larga influencia que el educador puede desempeñar como mediador entre la cultura y el mundo de la vida, entre los valores formativos y la experiencia de las generaciones. Y este regressus es una especie de bucle que permite jugar al autor con varios tiempos, desde los del remoto mundo clásico a los de la reciente posmodernidad, para ir en busca de una nueva construcción de la subjetividad o, mejor dicho, de las dos subjetividades, porque en este excurso dialéctico se están planteando las bases para definir la nueva condición del enseñante y la nueva condición de sujeto que aprende y se forma.

Me ha llamado la atención, en este contexto de consideraciones, la referencia que con especial énfasis hace Fernando Bárcena a un profesor que ejerció sobre él un especial y decisivo influjo en sus años de formación universitaria, en torno a los ochenta del siglo XX. Un profesor que curiosamente también lo fue mío, quince años antes: Federico Gómez Rodríguez de Castro. Confiesa Bárcena que aquel profesor de historia de la educación, tal vez algo desordenado en sus clases, pero muy motivante en sus exposiciones, supo encender en su ánimo la dormida y virtual vocación por la docencia en pedagogía con la que tal vez él ya acudió a este tipo de estudios. Entre sus años y los míos hay casi una generación de distancia, pero yo también conservo la imagen de que aquel profesor, recién retornado de Alemania entonces, era portador de un nuevo lenguaje y un nuevo ethos formativo. Sustituía un día a la semana al catedrático numerario de Didáctica, un escolástico de vieja escuela que trataba de construir la disciplina mediante la glosa de una selección de aforismos latinos, implementados con algunas teorías de la filosofía alemana de entre siglos, de raíz herbartiana, influencia neokantiana e impronta en algunos casos espiritualista, que se habían introducido en la España de posguerra con las traducciones de las obras de Willman, Paulsen, Schmieder (este por vía argentina) y otros. Los planteamientos de aquel profesor numerario se soportaban porque solían ir adobados con humor, pero no sintonizaban ya con las sensibilidades emergentes en una juventud que empezaba a sentirse incómoda con los formalismos dogmáticos de los académicos de la posguerra. El lenguaje del nuevo profesor, en cambio, hablaba de la didáctica con nuevas bases en la 
teoría de los signos y los símbolos, así como en la antropología cultural de los juegos de Caillois y Huizinga y de los rituales sociales. ${ }^{4}$ No es este el lugar para profundizar en este cambio, que por lo demás estoy reconstruyendo desde la memoria, para no sobrepasar los límites de una recensión, pero sí de subrayar que aquellos nuevos lenguajes operaron como los estímulos de seducción que ponía en acción un buen maestro para fundar una cierta philía con sus alumnos. En esta perspectiva, el profesor Federico Gómez pudo desempeñar el rol de influencer, un término que hoy ha cobrado vigencia para destacar la competencia, credibilidad e influencia de determinadas personas sobre los sujetos y colectivos en los que se proyecta su mensaje. El libro de Fernando Bárcena tiene como subtítulo Anatomía de una influencia y podía haberse extendido a este tipo de análisis que llevan a la consideración del educador como médium y, a la vez, como influencer.

La obra de Fernando Bárcena Maestros y discípulos es una especie de texto-vida, en buena medida autobiográfico, que se configura en torno a dos fuentes: su memoria personal del ejercicio de la profesión de enseñante universitario y su bien nutrida biblioteca de intelectual de nuestro tiempo, en la que comparten anaqueles los clásicos del pensamiento, y de la educación, con los modernos y posmodernos, desde Sartre-Gusdorf hasta Nietzsche-Arendt-Foucault, y en lo literario desde Camus-Proust-Mann hasta Pennac. Conviene señalar que es difícil adscribir a estos últimos solo al plano de lo literario, como también lo es confinar a Luchino Visconti y su obra Muerte en Venecia en la esfera del arte cinematográfico. Unos y otros forman parte sin duda de la intelligentsia más preclara del último siglo y entre todos podrían llegar a configurar, si hubieran coincidido en el espacio y en el tiempo, una especie de comunidad hermenéutica que nos ayudaría a leer y entender mejor las complejidades en que se ha visto envuelta en su época la educación y sus agentes personales, el maestro y el sujeto en formación. No se puede pensar la profesión de formador ni la condición de estudioso o aprendiz sin una biblioteca, un lugar-existenciario en el que se puede experimentar el valor de la soledad y también ejercitar la libertad de leer y pensar. Mis últimos años los estoy viviendo así, entre los miles de libros que me rodean, y ello me parece un don y un privilegio, como le pareció al Borges que imaginaba

\footnotetext{
${ }^{4}$ Federico Gómez Rodríguez de Castro, El valor didáctico del símbolo (Madrid: Ministerio de Educa-
} ción y Ciencia, 1966). 
el paraíso bajo la especie de una gran biblioteca. El arquitecto que diseñó el colegio Europa de Barcelona, pasada la mitad del siglo XX, al que asistió como alumno adolescente el conocido museógrafo Jorge Wagensberg, de cuyas memorias tomamos la referencia, situó la biblioteca en la encrucijada de corredores o pasillos del interior del edificio escolar, un punto crítico por el que habían de pasar necesariamente alumnos y docentes varias veces al día. ${ }^{5}$ Las cubiertas de los nuevos libros, que cada semana renovaban el interfaz de los expositores, fueron el mejor estímulo para incentivar, de manera subliminar si se quiere, el deseo por la lectura.

Al terminar de leer el libro de Fernando Bárcena uno saca la impresión, como bien destacó el moderador de la sesión online, de que el profesor tiene que llegar al final de su dilatada vida académica, cuando las sucesivas cohortes de alumnos ya han asumido su carta de libertad, para tomar conciencia del significado que adquiere el vínculo que ha supuesto la philía maestro-discípulo. Todo parece, pues, que se comprende mejor desde el final de un largo proceso de sucesivas influencias mutuas, porque entonces será el educador, transformado ahora en narrador, el que recapitule el haz de experiencias y emociones que ha ido experimentando a lo largo de la vida profesional. Como indicaba Hannah Arendt, siempre será el autor-narrador de su propio relato biográfico quien mejor pueda encontrar el verdadero sentido de la acción.

Hay en el texto de Fernando Bárcena otro transversal discursivo que no debo dejar de comentar: el recurso a la tragedia como modo de expresión no solo literario sino existencial y como componente relacional de la convivencialidad entre alumnos y maestros. Los filósofos adscritos a la orientación hermenéutica se suelen clasificar, entre ellos mismos, en dos grupos: los analíticos y los trágicos. También los hay eclécticos. Los primeros son más aristotélicos y se mantienen en el plano del análisis empírico y formal de los hechos que observan, analizan e interpretan. Los segundos consideran que la relación maestro-discípulo sucede en un mundo de vida en cierto modo sacralizado, en el que operan algunas dimensiones trágicas con sus ritos, cercanos a veces a la hierofanía (el maestro como mago, sacerdote o guía espiritual). Tómese esta atribución trágica en el contexto del género tragedia en el mundo antiguo y

\footnotetext{
5 Jorge Wagensberg, Algunos años después (Barcelona: Ars Llibres, 2014).
} 
en el marco de las reinterpretaciones que hicieron de ella intelectuales como Nietzsche y Steiner, entre otros. La dramatización de las conductas de los actores les otorga además un carácter público y ejemplarizante, aunque la filosofía —según Platón- siempre pudiera servir de antídoto para distinguir la ficción de la realidad, la apariencia del ser verdadero. En Aristóteles, lo trágico es una mímesis de la acción que purifica las emociones mediante la catarsis. Para Nietzsche, la música, una disciplina de carácter estético, ayuda a transformar el sentimiento trágico en compasión, lo que mitiga el sufrimiento por el dolor de la verdad. Bárcena se define hoy como profesor y como músico porque divide su vida entre estas dos pasiones, afines o complementarias entre sí. Toda la estética de la tragedia representada, la mise en scène, contribuirá si se quiere a reforzar la función pedagógico-moral de las representaciones teatrales de lo trágico, si es con música mejor, en la medida en que esta podrá estimular el ethos entusiastikon a que aludían los griegos. De este modo, los ritos y las ceremonias que asumen educadores y alumnos en las despedidas finales son a la vez instrumentos de racionalización de las mismas despedidas.

Pues bien, retomando los escritos del filósofo Manuel Garcia Morente, datados ya hace casi un siglo, entre 1924 y 1936, ${ }^{6}$ el autor de este ensayo trata de inscribir la «vocación» y la «tragedia» del maestro que al final ha de despedirse del discípulo por imperativo pedagógico como un juego ritual entre el eros y el dolor. Curiosamente, estos escritos de García Morente eran referidos en sus clases por el que fuera en la posguerra catedrático de Pedagogía General de la Universidad de Madrid, el profesor Romero Marín, que a la sazón también fue profesor mío, quien, tras combinar a Herbart con Dewey, terminaba su curso con esta reflexión del en otro tiempo ilustre decano en la época dorada de la Facultad de Filosofía y Letras. «El maestro es el hombre de las despedidas», concluye Fernando Bárcena concordando con Morente al finalizar el capítulo intitulado «La dimensión trágica». Es misión del educador acompañar y tutelar al alumno en su iniciación al mundo de la vida y del oficio docente si es el que ha elegido, pero al final del proceso, abnegado para no sucumbir en el inevitable duelo (otro ritual que forma parte de toda tragedia), ha de ausentarse de la escena haciendo mutis por el foro

\footnotetext{
${ }^{6}$ Manuel García Morente, Escritos pedagógicos (Madrid, Espasa Calpe, 1975).
} 
para que el discípulo amado se emancipe en condiciones de libertad. He aquí un planteamiento finalístico que introduce la ética y estética en la construcción del discurso filosófico acerca de la educación, como en el pensamiento griego, muy socrático, en el que el autor siempre gusta de apoyarse. En la despedida, el maestro ya ha contagiado su humanidad al discípulo, con la complicidad de este, como advierte también Fernando Savater en El valor de educar, ${ }^{7}$ para que el otro pueda llegar a ser el que es, según el conocido aforismo, otro desiderátum por lo demás de clara filiación con el humanismo clásico.

Cambiamos ahora de tercio y retomamos los trabajos del profesor Jorge Larrosa antes referidos acerca del profesor y de su oficio.

Hace ahora justamente un año, en los días finales del mes de enero de 2020, desarrollamos en el CEINCE el último coloquio antes de entregarnos al largo encerramiento de la crisis pandémica que se iniciaría un mes después, sin que nadie por aquellas fechas entreviera que escuelas y profesores se iban a ver sometidos a cambios tan impactantes y de tan larga duración. El seminario, coordinado precisamente por el mismo profesor Jorge Larrosa Bondía, llevaba por título «Elogio de la escuela», aunque pudo haber llevado igualmente el de «Elogio del profesor», y trató de reconstruir, en perspectiva comparada e internacional, las prácticas y los materiales que han llegado a configurar la cultura empírica de la escuela y el arte de enseñar, así como su correlativo modo de aprender. Jan Masschelein, profesor de Lovaina, planteó en su intervención el elogio de la escuela como un discurso fundamentado en la misión que esta ha venido cumpliendo históricamente en la implantación comunitaria de la lengua como modo esencial de construcción de la nacionalidad de un pueblo, un hecho de alcance civilizatorio y universal que acredita su permanencia en el tiempo. Profesores y profesoras de Brasil, Argentina, Bélgica y España analizaron, en formato workshop, los objetos o materiales (principalmente manuales escolares e iconografías) y las prácticas que han ido configurando la acción formativa y el oficio docente. Ninguno de los participantes puso en cuestión esta vieja profesión, ni advirtió siquiera que pudiera ser cuestionada o amenazada con su desaparición. Tampoco creo que se pudiera hacer esta advertencia unos meses después, tras los impactos recientes de la pandemia y los

\footnotetext{
${ }_{7}^{7}$ Fernando Savater, El valor de educar (Barcelona: Ariel, 1977).
} 
cambios efectuados en la gobernanza de las instituciones de educación formal, en los roles de los profesores y en las formas de trabajo de los estudiantes. En el animado conversatorio que se suscitó durante el coloquio no se observó elogio hagiográfico alguno ni alusiones que pudieran conducir a formas de sacralización de la profesión, aunque el término elogio sí constituyó un leitmotiv orientador del trabajo y la discusión. Más bien, el dominante heurístico de este grupo consolidado de investigación se dirigió al examen de las prácticas que han orientado tanto la construcción de la cultura empírica de la escuela como las artes y el habitus de los formadores. Y este mismo corte discursivo es el que marca los trabajos del profesor Larrosa que pasamos a comentar.

Empezamos por glosar el primer libro de la trilogía, el que lleva la marca de $P$ de Profesor. Es este un volumen, de cerca de quinientas páginas, en forma de vocabulario o diccionario que glosa, en dialogo de Jorge Larrosa con su interlocutora Karen Rechia, colega de Florianópolis (Brasil), quien también participó en el referido coloquio del CEINCE, los términos en que se condensan y analizan los modos de ejercer el oficio de enseñante, o las maneras de practicar la docencia. Se trata pues de un trabajo etnográfico que traduce en palabras la fenomenología de los hechos registrados en la bitácora. De las facticidades a las palabras. Esta es la traslación que hace la operación etnográfica. Y de las palabras a la dialéctica en torno a cada una de ellas mediante el debate. Tal es el método con que los autores se enfrentan al trabajo realizado. La contracubierta del libro habla de una fenomenología textual, que es a la vez un análisis de la experiencia observada. Antonio Rodríguez, comenta el catálogo de herramientas, dispositivos y conductas que, al igual que en esta dupla docente, podrían haber encarnado en otros sujetos, en sus maneras de pensar, de decir y de hacer dentro del campo de la profesión de enseñante.

Un conjunto de setenta y cuatro términos, dispuestos en orden alfabético, conforman este glosario analítico de la profesión docente que va desde las categorías alumno-aula-autoridad a las de tiempo-universidad-vejez. Veamos, a modo de ejemplo, dos de ellas, seleccionadas entre las que más directamente afectan a los modos operativos de ejercer el oficio de profesor o enseñante: artefacto y oficio.

$\mathrm{Al}$ encontrarme con el término artefacto — comenta Karen Rechiame he acordado de mi abuelo, un hombre de varios oficios y de muchas 
herramientas, cada una de las cuales ocupaba su lugar en su taller hasta que él mismo la buscaba para hacer alguna tarea de oficio. Cada ocupación o modo de hacer tiene su caja de herramientas, sus artefactos. Asimismo, el oficio docente tiene los suyos, esos que ahora denominamos a menudo tecnologías educativas y en otras ocasiones recursos o materiales didácticos. Artefacto-artífice-artilugio-artimaña-artesanía configuran algo así como un convoy semántico que hace referencia a los modos de practicar las artes del oficio de profesor. Algunos las han asociado a las prácticas de bricolaje y otros han definido determinados materiales como tecnologías vernáculas. Hoy, como es sabido, el estudio de la cultura material de la escuela es una corriente historiográfica en expansión que busca el descifrado de los códigos semióticos que residen en los objetos y artefactos que han formado parte de la empiría de la educación, es decir, de las artes de la enseñanza y de las prácticas de aprendizaje. ${ }^{8}$ El aula es el lugar al que, como dice la filósofa María Zambrano, se va a aprender de oído. ${ }^{9}$ Ella es como el escenario de un concierto, donde los textos serían la partitura o guion de la composición y los artefactos los instrumentos, comentan los autores que la citan.

Otro término a comentar: oficio. Es este el modo o manera de hacer: el conjunto de prácticas que forman el habitus, la costumbre y el ethos de la profesión. El saber hacer es la forma, a menudo ritualizada, incluso con códigos litúrgicos, como parece sugerir el filósofo Giorgio Agamben, con la que el maestro se constituirá en el oficiante y la escuela en la oficina de trabajo. ${ }^{10}$ Comenio definió el aula de la escuela, en el Orbis sensualium pictus, como officina en la que se dispensan los saberes a los discípulos sedentes dispuestos ordenadamente en bancos y mesas. El maestro oficia como profesor siguiendo ciertas reglas técnicas que son en parte independientes del sujeto que las aplica, quien, al ponerlas en práctica escolar, las celebra en cierto modo como pautas de una devotio, comenta a la vez Agamben, que es al tiempo manifestación de respeto por la tradición del oficio asumido, de conformidad con el impulso en favor de las cosas bien hechas, con acreditada maestría u oficio y con

\footnotetext{
${ }^{8}$ Agustín Escolano Benito, Repensar la cultura material de la escuela (Zacatecas-México: Publicaciones de la Benemérita Escuela Normal de Maestros, 2021).

9 María Zambrano, Textos pedagógicos (Barcelona: Publicaciones Universidad, 2002).

10 Giorgio Agamben, El uso de los cuerpos (Buenos Aires: A. Hidalgo, 2017).
} 
encarnación en el mismo cuerpo del sujeto, como destaca en otro sentido Richard Sennett en su obra El artesano. ${ }^{11}$

El valor de la práctica del oficio es el transversal que el escritor Frank McCourt sostiene en el entramado de su conocida novela El profesor, un relato que recoge las confesiones de un experimentado enseñante al final de su ejercicio profesional. «El camino de la pedagogía es largo. Soy un profesor nuevo y estoy aprendiendo con la práctica. Jugueteo con los instrumentos de mi nuevo oficio». Y añade: «Según mis cálculos, unos doce mil chicos y chicas se han sentado en pupitres, y me han oído explicar, cantar, animar, divagar, declamar, recitar, predicar... Impartí al menos treinta y tres mil clases. Treinta y tres mil en treinta años». «En la universidad había asignaturas que trataban de cómo enseñar, impartidas por catedráticos que no sabían enseñar. Hablaban de teorías y filosofías de la educación, de imperativos morales y éticos, de la gestalt... Yo aprendí por prueba y error». Asimismo, «me sentí incómodo con los burócratas, que habían huido de las aulas. Nunca quise ceñirme a sus programas y a sus planes». ${ }^{12} \mathrm{Ni}$ los teóricos ni los administradores eran para McCourt gentes de oficio, y por eso los desestimaba.

Así pues, por ensayo y error, jugando en la práctica con las herramientas materiales del oficio de enseñante y con las retóricas comunicativas de la cultura escolar, hora tras hora y año tras año, rehusando o adaptando a las propias necesidades y expectativas las teorías de los académicos y las normas de los burócratas, forjó el profesor Frank McCourt el arte y oficio de enseñante. Y así también — siguiendo la lógica de la racionalidad práctica de que habla Pierre Bourdieu-,13 la mayor parte de los profesores fueron construyendo las reglas del oficio docente en las que forjaron su habitus de trabajo y con las que guiaron, con rigor y método, la larga aventura del aprendizaje de los alumnos que estuvieron a su cuidado.

Todo lo anterior enlaza justamente con el segundo de los volúmenes que nos ha donado el profesor Jorge Larrosa que tiene un título que parece sugerir cierto escepticismo de partida pero que es en realidad un

\footnotetext{
${ }^{11}$ Richard Sennett, El artesano (Barcelona: Anagrama, 2009).

12 Frank McCourt, El profesor (Madrid: Maeva, 2006).

${ }_{13}$ Pierre Bourdieu, El sentido práctico (Madrid: Siglo XXI, 2007).
} 
pretexto retórico para relanzar el elogio de la escuela, antesala también del consiguiente elogio del oficio de profesor. La apología de la escuela, como entorno de la vida del formador, es abordada desde el reconocimiento de que, aunque "los tiempos están cambiando» (primer enunciado tomado de la conocida canción de Bob Dylan), hay que salvar el «trabajo bien hecho» a que alude Peter Handke, el mentor literario que presta al autor microtextos de entrada a cada capítulo del libro y varias referencias citadas ad hoc. ${ }^{14}$ Importantes intelectuales preludian la sintonía de este libro, bien escrito y sugerente, para tomar de él numerosos puntos de reflexión y debate.

Es este un trabajo que merece, como señala Joan Carles Mèlich, miembro también del «colegio invisible» al que hemos hecho referencia, el salvamento de las escuelas y de los docentes que, amarrados en tradiciones centenarias, dignifican su viejo oficio de formar, frente a las amenazas de verse engullidos por las estrategias de los gestores que juegan a favor del capitalismo cognitivo, el desarrollo de las competencias performativas y la gestión de las emociones pro domo sua. Con fuentes, en parte comunes a las del anterior ensayo de Fernando Bárcena, y en parte también diferentes, Jorge Larrosa se debate contracorriente tratando de afrontar el malestar de la educación de nuestro tiempo con el elogio de la autoridad simbólica del profesor y de la episteme praktike en que se sustenta la dignidad y la eficiencia del buen hacer de tan acreditado y elogiado oficio. La referencia a la pragmática de la profesión de maestro o enseñante habla bien del nuevo empirismo con que es examinada aquí la cultura de la escuela.

Más de cuatrocientas densas páginas, como el volumen anterior, permiten a su autor analizar y profundizar en las señales observables de la nueva crisis de la escuela, en la que los viejos y buenos enseñantes aparecen casi siempre como actores sospechosos que no se pliegan bien a las reglas de la performance tecnoeconómica, tal vez para impedir desde su resistencia, instintivamente pero con intuicionismo soteriológico, que el mundo se deshaga, o se deconstruya hasta el punto de no poder reconocerlo, y para reafirmar con su testimonio apoyado en buenas tradiciones que, según advirtió Peter Handke de nuevo en su conocida Historia del lápiz, solo trasmiten cultura quienes aman la querida escuela. ${ }^{15}$

\footnotetext{
${ }_{14}$ Peter Handke, El juego de las preguntas (Madrid: Alfaguara, 1992).

15 Peter Handke, Historia del lápiz, (Barcelona: Península, 1991).
} 
La escuela, esa importante invención griega, como la democracia y como la filosofía, se salvará si es capaz de mantenerse con cierta independencia crítica, en sus espacios y en sus tiempos, y en parte a cierta distancia de la familia y de la comunidad envolvente, esto es, con autonomía relativa, como un espacio público diferenciado de las comunidades de base y del Estado. Jorge Larrosa dedica un capítulo al «elogio del aula», ese lugar cuasi sagrado presidido por el retablo-pizarra y algunos símbolos, en el que oficia el maestro, conviven los pares de edad y se lleva a cabo la mediación del educador con la nueva generación de sujetos, cada año renovada. Recuérdese a este efecto la conocida obra de Marcelo Caruso e Inés Dussel intitulada La invención del aula. ${ }^{16}$ Todo este extenso espacio textual de libro, que el autor escribe en abierta conversación con colegas como Joan Carles Mèlich y Fernando Bárcena (del mismo grupo al que ya aludimos), y con autores siempre presentes en su biblioteca intelectual como Handke, Arendt y Zambrano (y muchos más), es un rico arsenal de ideas para salvar el escenario sagrado de la clase, al que Larrosa atribuye muchas dimensiones de cultura, ritualidad y sociabilidad, las llaves antropológicas que son firmes anclajes civilizatorios, por su asentamiento histórico, y porque sirven de soporte a los dos sujetos implícitos del escenario compartido, el alumno y el profesor.

No nos entretenemos en más comentarios a esta importante obra, que requeriría una glosa aparte por muchas razones, para no desequilibrar la recensión del conjunto de estas cuatro piezas librarias y para dar entrada finalmente al volumen que más afecta al sentido de estos comentarios. El libro final de la trilogía de Jorge Larrosa lleva por título El profesor artesano. Materiales para conversar sobre el oficio. De nuevo el sujeto-enseñante recupera centralidad en la escena, y lo hace acompañado de los elementos materiales y simbólicos que acompañaron sus trabajos y sus días, de sus herramientas, así como a través de un conversatorio que el autor entabla y mantiene con los intelectuales que pueblan su memoria y su biblioteca, así como con los colegas con quienes comparte las experiencias y los compromisos de afinidad hermenéutica.

Como siempre, Peter Handke se coloca en las cabeceras de textos preludiando capítulos, pero ahora el mentor transversal de mayor peso

\footnotetext{
16 Inés Dussel y Marcelo Caruso, La invención del aula. Una genealogía de las formas de enseñar (Buenos Aires: Santillana, 1999).
} 
en el conjunto de esta obra es probablemente Richard Sennett, un sociólogo que desde que escribiera su lúcida crítica a las corrosiones suscitadas por el capitalismo industrial en el carácter de los ciudadanos y en la evolución de los modos de trabajar que definieron las profesiones tradicionales, y aún las modernas, se ha hecho imprescindible para la historia de los oficios y para explicar las formas de sociabilidad en que estos se fundamentan. Su última trilogía traducida hace pocos años en Anagrama (El artesano, Juntos y Habitar la ciudad) son libros de cabecera de muchos para acercarse a la cultura empírica de cualquier ámbito profesional, también del que se refiere al ejercicio de la enseñanza.

Curiosa anotación: en la literatura, la figura del profesor, o del maestro, aparece casi siempre acompañada de la de zapatero, músico, carpintero... No solo la literatura. La antropología, el cine, la filosofía, y desde luego la pedagogía, también la incorporan en sus textos. Roland Barthes afirmaba que cuando las personas hablaban de su oficio, cualquiera que fuese, nunca se aburrían. A él le afectaba expresamente la práctica material de la escritura, que era su oficio. Las formas de vida, apunta Giorgio Agamben, no son maneras a priori preexistentes a la acción, sino modos operantes que se generan viviendo. Y estas construcciones empíricas se suelen llevar a cabo con herramientas, en el caso de la forma escolar en el marco del aula y por el profesor, quien con las experiencias que el tiempo acumula y condensa perfila su oficio de enseñante. Jorge Larrosa trata de eludir el término profesión, que considera contaminado por la ideología del profesionalismo, y prefiere usar el de artesanía, porque esta alude a materialidad, tradición, subjetividad, corporalidad, maestría y obra bien hecha, en el sentido que le da a esta expresión Richard Sennett. Y a la vez alude a habitus, que afecta al tiempo a un ethos o modo de vida vigente en toda la cotidianidad y ejercido por toda la corporación del oficio con cierta devoción o respeto por las costumbres.

En la base de toda esta concepción del oficio docente está la experiencia, o empiría, entendida esta como una relación pragmática con el mundo o, si se quiere, como una visión empírica del modo de estar-enel-mundo. La cultura empírica de la escuela, en la que se inserta el oficio de la enseñanza, sería en este sentido una especie de saber corporeizado, incorporado o encarnado, es decir, un repertorio de formas prácticas de hacer que además están estrechamente vinculadas a las materialidades del trabajo, esto es, a los espacios y artefactos de uso escolar, muchos de 
ellos inventados por los propios maestros. Todo ello demanda una aproximación etnográfica o fenomenológica a la historia y al ejercicio del rol de profesor, así como a las formas vernáculas de sus modos de expresión. Lo vernáculo, como indicó Iván Illich, se propaga en la práctica de lo cotidiano, como la lengua materna y los modos de comunicación entre los actores que desempeñan un oficio. Esta encarnación en el cuerpo de quienes construyen y detentan un oficio podría enmarcarse a la vez en el cuadro teórico de los cuatro existenciarios en que Max van Manen sitúa la escuela: la misma corporeidad del maestro oficiante y de los cuerpos de los aprendices (los sujetos); los espacios en que se desenvuelve su acción (el ecosistema); los tiempos o cronogramas del cotidiano (el proceso); y la relacionalidad con los sujetos con quienes se interacciona (sociabilidad). ${ }^{17}$ Este planteamiento, también de corte hermenéutico, es una reducción fenomenológica que pudiera servir tal vez para estructurar los datos de la experiencia etnográfica, bajo la perspectiva de una historiografía de clara vocación intelectual.

Jorge Larrosa se sirve, una vez más, del análisis que Richard Sennett hace de los gestos y las acciones que comporta el oficio de panadero, un campo que a mí personalmente me es bien conocido porque lo viví y lo practiqué, en el seno de mi núcleo familiar, antes de su modernización tecnológica. A esta experiencia vivida debo probablemente mi inclinación hacia los análisis empíricos de la vida y de la cultura, como he tratado de aplicarlo en mis últimos trabajos a la cultura de la escuela. Puede que muchos de los cambios que se han operado en este sector de la elaboración del pan, al tecnologizarse, sean extrapolables a las mudanzas observables hoy en el trabajo de los docentes, en paralelo con la puesta en acción de nuevas prácticas de performatividad técnica.

En efecto, la panadería ha sido un arte que cohesionó durante varias generaciones a los artesanos que la practicaron, constituyendo una tradición artesana. La elaboración del pan — dice Richard Sennett—era un ejercicio coreográfico, plasmado en el bullicio de los obradores, en los olores de sus materias primas y elaboradas, cambiantes en cada fase de la producción, en la motricidad de las manos operarias, en la sensibilidad visual, olfativa y táctil de los trabajadores para percibir los cambios en los estados del proceso de manipulación de las materias primas, en

\footnotetext{
17 Max van Manen, El tacto en la enseñanza (Barcelona: Paidós, 1998).
} 
el control del fuego y el calor. Todo esto ha cambiado radicalmente en los nuevos modos de fabricación en cadena, en los que los obreros de una panadería, sin herencia-tradición de oficio, se limitan a seguir en pantalla las instrucciones que ordenan los iconos que pautan el proceso de fabricación. Ello ha afectado a la identidad de los panaderos como gremio y como sujetos artesanos, así como a la reaparición posterior de algunas formas de producción que pueden ser comprendidas como trabajos más conformes con los tiempos y movimientos del viejo arte de la panadería, esto es, como salvaguardas de la mejor tradición perdida.

En el oficio docente también se están dando este tipo de cambios. Los enseñantes están cada vez más sujetos a procesos de diseño, programación y control en el ejercicio de su actividad, a la vez que implementados, y a veces sustituidos, por productos tecnologizados externos que no siempre se acomodan a la marcha de la clase ni a las necesidades de los sujetos, a las formas artesanales de trabajo y a los modos vernáculos e informales de comunicación. Ello lleva a una cierta mecanización técnica de la relacionalidad entre los sujetos, y a mudanzas importantes en el uso de los espacios y los tiempos de alumnos y docentes, que afectan incluso a la misma corporeidad de los sujetos, y por tanto a la identificación de los enseñantes con el oficio que desempeñan, que puede estar también amenazado por las mediaciones de la ciberescuela. Algo de esto sucedió en la revolución del audiovisual, en los años sesenta y siguientes, que coincidió con la emergencia de la enseñanza programada y las máquinas de instrucción, la que suscitó la obra de Gusdorf que motiva el trabajo de Bárcena, aunque reformas posteriores trataron de inducir nuevas formas de humanización de un oficio que nunca podrá ser mecanizado sin afectar al juego entre libertad y tradición.

Existen manualidades inteligentes que conectan el homo sapiens con el homo faber (de nuevo Sennett). Este sociólogo sí que es sapiens sapiens. Y, además, si los objetos se hacen en cooperación (Juntos es el título de su segunda obra del sociólogo anglosajón), ${ }^{18}$ el oficio pasa a ser un saber corporativo y una tradición, lo que aconseja la transmisión asegurada de las reglas de trabajo en comunidad y una cierta continuidad histórica, al tiempo que salvaría los muebles que recuperan algunos de los valores de la resistencia sin renunciar al sueño de la innovación.

\footnotetext{
18 Richard Sennett, Juntos (Barcelona: Anagrama, 2012).
} 
Numancia (la ciudad de la resistencia) y Samarkanda (la de los sueños), como diría Peter Handke, dos lugares que él ha conocido bien sobre el terreno, el otro interlocutor que se relaciona incluso personalmente con Jorge Larrosa, atento y sutil visitante de estas tierras de Celtiberia.

Quedan muchas cosas por glosar, pero quiero pensar que estas notas serán suficientes para motivar la lectura de este libro (y de los otros tres). El conjunto editado que suma más de mil quinientas páginas, y que debería entrar a formar parte de la biblioteca intelectual de todo enseñante y de quienes se ocupan de historiar las viejas y siempre cuestionadas tareas de la formación. Yo desde luego siempre los tendré a mano para volver sobre ellos cuando las preguntas me acechen y me remitan a sus propuestas.

Agustín Escolano Benito Centro Internacional de la Cultura Escolar (CEINCE) aeb05@telefonica.net 